\title{
Genetic Susceptibility to West Nile Virus and Dengue
}

\author{
M. Loeb \\ Department of Pathology and Molecular Medicine, McMaster University, Hamilton, Ont., Canada
}

\section{Key Words}

Epidemiology · Genetic · Genomic analysis of complex diseases

\begin{abstract}
This article focuses on the host genetic predisposition to 2 viruses, West Nile virus and dengue virus, which belong to the genus Flavivirus. Although by definition these viruses have shared characteristics (e.g. similar size, single stranded, RNA viruses, both transmitted by the bite from an infected mosquito), they differ greatly in epidemiology and clinical manifestations. The text below not only summarizes the genetic factors that predispose to complications of these $2 \mathrm{im}$ portant flaviviruses, but also illustrates the challenges in determining the genomic basis for complications to these viruses.

Copyright $\odot 2013$ S. Karger AG, Basel
\end{abstract}

\section{West Nile Virus}

Serious clinical illness due to West Nile virus (WNV) emerged rather dramatically in North America, beginning with a large outbreak in New York City in 1999. Since that time, WNV emerged as an important human pathogen in North America, where it eventually became reported in a majority of states and provinces in the US and Canada [1]. Although the incidence of reported cases has changed from year to year, the severe complications that can occur in infected cases remain a concern. It is notable that of those infected with this virus, approximately $20 \%$ develop mild symptoms, so-called 'West Nile Fever' which is characterized by manifestations such as fever, malaise, headache, myalgia, and rash. Only 1 in $\sim 150$ individuals who are infected develops meningitis or encephalitis [2]. This is suggestive for a genetic susceptibility in humans. The incidence of severe neurological syndromes increases with age (this includes encephalitis, meningitis, acute flaccid paralysis, peripheral neuropathy, polyradiculopathy, optic neuritis, and acute demyelinating encephalitis) and with immunosuppression. The absence of other well-defined risk factors again suggest that there is an underlying genetic predisposition to complications of disease.

Unlike dengue, where there is no animal model, there have been experiments in mice to try to establish a locus for susceptibility. Innate resistance to flavivirus-induced morbidity and mortality was first demonstrated in mice in the 1920s and showed monogenic autosomal dominant inheritance. These mice are susceptible to infections with other viruses but are resistant to all flaviviruses. Furthermore, within the mouse genus Mus, susceptibility to West Nile virus experimental infection is completely correlated with the occurrence of a point mutation resulting in the truncation of the $2^{\prime}-5^{\prime}$-oligoadenylate synthetase

\begin{tabular}{ll}
\hline KARGER & $\begin{array}{l}\text { (c) } 2013 \mathrm{~S} \text {. Karger AG, Basel } \\
\text { 1662-4246/13/0162-0004\$38.00/0 }\end{array}$ \\
$\begin{array}{l}\text { E-Mail karger@karger.com } \\
\text { www.karger.com/phg }\end{array}$ & $\begin{array}{l}\text { This is an Open Access article licensed under the terms of } \\
\text { the Creative Commons Attribution-NonCommercial-No- } \\
\text { Derivs 3.0 License (www.karger.com/OA-license), applica- } \\
\text { ble to the online version of the article only. Distribution for } \\
\text { non-commercial purposes only. }\end{array}$
\end{tabular}

Mark Loeb

Department of Pathology and Molecular Medicine, McMaster University 1280 Main Street West

Hamilton, ON L8N3Z5 (Canada)

E-Mail loebm@mcmaster.ca 
$\left(2^{\prime}-5^{\prime}\right.$-OAS) L1 isoform. This would suggest that this enzyme is relevant in $\mathrm{WN}$ pathogenesis through an effect restricting viral replication in target tissues [3]. Indeed, the cluster of genes encoding $2^{\prime}-5^{\prime}$-OAS has for many years been seen as a prominent candidate locus since they encode a multimember family of IFN-inducible proteins known to play an important role in the established endogenous antiviral pathway.

There have been a limited number of human association studies to assess susceptibility to complications of West Nile virus or risk of infection to West Nile virus. One study from Texas analyzed 33 West Nile virus infected individuals who had developed either fever, meningitis or encephalitis [4]. They were compared to 60 healthy controls from an available database. The study identified one synonymous SNP in OASL exon 2 (rs3213545) as being at significantly higher frequency in the cases compared to the controls $(<0.004)$; however, no adjustment was made for multiple testing and there was no attempt at replication. More recently, another candidate gene study examining the OAS gene cluster alone again suggested a predisposition to WNV infection [5]. This study compared OAS variants in a cohort of symptomatic individuals (fever, meningitis, encephalitis) and asymptomatic but infected individuals identified through a blood donor bank to a noninfected cohort. There were no genetic variants associated with severity of disease, in keeping with a larger association study that was recently reported [6]. However, the authors reported that rs 10774671 was significantly more frequent in West Nile virus infected than noninfected individuals $(\mathrm{p}=0.0002)$. Limitations include the fact that there was no adjustment for multiple testing, and the results were not replicated in a separate cohort, although this SNP did have an effect on viral replication in an ex-vivo model of primary human lymphoid tissue [5]. One study compared symptomatic to asymptomatic individuals with $\mathrm{WNV}$ infection and found that SNPs in the interferon pathway (IRF3 and MX1) were associated with symptoms [7]. In contrast to other studies that examined complications, they also found that $O A S 1$ was associated with an increased risk for encephalitis and paralysis.

An association between symptomatic WNV disease and homozygosity for the CCR $5 \Delta 32$ mutation in the chemokine receptor gene CCR5 was initially reported $[8,9]$. However, this association was not replicated, but was suggestive of a link to clinical manifestations of infection with CCR5 $\triangle 32$ mutation [10]. Moreover, in a recent large association study (560 neuroinvasive cases and 950 controls, and a replication cohort of 264 cases and 296 con-

Genetics and West Nile trols) no such evidence for an effect was noted [5]. One possible reason for the discrepancy is that the latter study compared cases to controls all of whom were symptomatic when infected with WNV. In contrast, the published reports compared cases to controls with no symptoms.

\section{Dengue Virus}

Dengue virus (DENV) is found in tropical and subtropical regions around the world, predominantly in urban and semiurban areas. The public health burden is huge; it is estimated that 250 million people or two-fifths of the world's population are at risk from this virus. The World Health Organization currently estimates that there may be 50 million cases of DENV infection worldwide annually [11]. Dengue has become endemic in more than 100 countries in South-East Asia, the Americas, the Eastern Mediterranean, Africa, and the Western Pacific. Although the vast majority of DENV infections result in no symptoms or a mild febrile illness, approximately 500,000 dengue cases progress to life-threatening disease causing $20,000-25,000$ deaths annually. The clinical presentation may include fever and an influenza-like syndrome characterized by headache, retro-ocular and joint pain, rash, and lymphadenopathy; known as classic dengue or 'break-bone fever'. Following the febrile phase, the disease may progress to dengue hemorrhagic fever (DHF) characterized by thrombocytopenia and pleural and abdominal effusions, and dengue shock syndrome (DSS) (DHF with evidence of systemic hypoperfusion).

There are 4 antigenically and genetically distinct dengue viruses (serotypes 1-4) that cause similar disease in humans. This increases the complexity of determining the importance of host factors in causing severe illness. Following infection with dengue, viremia occurs for up to 6 days after onset of fever. Clearance of the virus is mediated by the development of a robust neutralizing antibody response against the infected serotype. As well, there is production of DENV-specific T cells that trigger removal of infected cells. The cardinal feature of DHF is plasma leakage potentially arising from proinflammatory cytokine-inflicted damage to the endothelium. Plasma leakage occurs late and coincides with clearance of the viremia, suggesting mediation through host response rather than direct virally-mediated tissue damage.

Neutralizing antibodies serve as the most common correlate of protection. These provide long-term protection against reinfection with homologous dengue. However, infection with a particular serotype confers only 
partial and transient protection against the other serotypes. Cohort studies provide good epidemiological evidence that secondary heterologous infection increases the risk of DHF. Antibody-dependent enhancement, where cross-reactive antibodies promote enhanced uptake of heterologous virus into host cells, has been proposed as the mechanism. First time infections are typically benign and self-limiting and rarely develop into DHF. Most subsequent, or secondary, infections with a different serotype also produce mild illness. However, $2-3 \%$ of secondary infections result in DHF. In children, the ratio of symptomatic to asymptomatic infection is estimated to be 1:40, although this ratio varies by population. Severe primary infection occurs predominantly in infants, after protective maternal antibodies wane to a level where they enhance disease rather than prevent it.

Less than $2 \%$ of individuals infected with dengue develop DHF. This suggests that host genetic factors may play an important role. Indeed, there is an absence of DHF/DSS in the Haitian population despite hyperendemic transmission of DENV serotypes. Similarly, multiple DENV serotypes circulate in West Africa, but there have been no reports of DHF. Furthermore, blacks were less likely to be hospitalized during Cuban DENV epidemics. Although preexisting immunity may be a confounding factor, these reports suggest that genetic predisposition is an important factor as well.

A number of genetic variants have been reported, and these will be discussed below. Dendritic cells (DC) are major in vivo targets of DENV. The DC Specific Intercellular adhesion molecule 3 Grabbing Non-integrin (DCSIGN), encoded by CD209, can confer DENV susceptibility to normally nonpermissive cells. It interacts with glycan moieties on the DENV E protein and mediates the entry of all 4 serotypes. The effect of a promoter variant of CD209, DC-SIGN-336, was assessed in a Thai study. The $G$ allele (GG or GA) of the variant DC-SIGN-336 was found to be infrequent (2\%) in 150 individuals with DF compared with 693 controls (12\%) (OR 0.20, 95\% CI, $\left.0.08-0.44, \mathrm{p}<10^{-4}\right)[12]$. No protective effect was seen in DHF (OR 1.19, 95\% CI, 0.88-1.61, p = 0.24). However, the $G$ allele was strongly associated with risk of DHF $(\mathrm{n}=150)$ when DHF cases were compared to DF (OR 5.88, 95\% CI, 2.56-15.33, $\mathrm{p}=1.4 \times 10^{-7}$ ). These findings, if replicated, may suggest distinct pathophysiological processes for DHF and DF, usually considered as a continuum.

Fc $\gamma$ receptor II is a widely distributed receptor for all subclasses of IgG. It can mediate ADE in vitro by binding to virus-IgG complexes. An arginine to histidine substi- tution at position 131 of the Fc $\gamma R I I$ gene has been associated with meningococcal disease and recurrent respiratory infections. This polymorphism changes the IgG binding affinity of the receptor, which reduces opsonization of IgG2 antibodies causally associated with the arginine variant. Homozygotes of the arginine variant in 302 cases of DSS (6\%) were compared to 238 healthy controls in Vietnam (11\%) [13]. Although the result was not statistically significant, OR $0.57,95 \%$ CI, $0.29-1.11, \mathrm{p}=0.07$, the confidence intervals do not rule out a potentially important protective effect.

The vitamin $\mathrm{D}$ receptor mediates the immunoregulatory effects of 1,25 -dihydroxyvitamin $\mathrm{D}_{3}\left(1,25 \mathrm{D}_{3}\right)$, which activates monocytes, stimulating cellular immune responses and suppressing immunoglobulin production and lymphocyte proliferation. The C allele of a SNP at position 352 of the VDR gene has been associated with tuberculoid leprosy, clearance of hepatitis B infection and resistance to pulmonary tuberculosis. In a study conducted in Vietnam, 327 children admitted to hospital in Vietnam with DSS were compared to 251 ethnically matched healthy controls [13]. Frequency of the variant VDR.I352 was $2 \%$ in cases compared to $3 \%$ in controls, suggesting a possible protective effect (OR $0.48,95 \% \mathrm{CI}, 0.21-1.09$, $\mathrm{p}=0.056$ ).

High levels of virus replication in monocytes and macrophages can result in elevated presentation of DENV epitopes to T cells. Evidence exists that the degree of activation of $\mathrm{T}$ cells correlates with disease severity. It has been suggested that TNF- $\alpha$, secreted by activated T cells, can directly affect the integrity of vascular endothelial cells. Since the hallmark of DHF is plasma leakage, genetic variants in the TNF- $\alpha$ gene may influence the outcome of infection. In a Venezuelan study, 25 patients with DHF were compared to 41 patients with DF for a SNP in the TNF- $\alpha$ promoter located 308 nucleotides upstream of a transcriptional start site [14]. The TNF-308 variant allele was present in $30 \%$ of participants with DHF versus $5 \%$ in those with DF (OR 7.58, 95\% CI, 1.23-79.2, p = 0.02). 4/4 patients with high TNF-a genotypes (TNF-308 AA or AG) and low Il-10 genotypes (IL10-1082:AA) had DHF. In a more recent study, the TNF-238A polymorphism marking the TNF-4, LTA-3 haplotype was found to occur in $15 \%$ of 132 ethnic Thais with secondary DHF compared to a frequency of $4 \%$ in 169 patients with secondary DF (OR 4.13, 95\% CI, 1.59-11.17, p < 0.001) [15]. Together, these data suggest that genetic variants leading to high levels of TNF- $\alpha$ together with low levels of antiinflammatory cytokines may be important in DENV pathogenesis. Furthermore, the association of TNF- $\alpha$ 
Table 1. Summary of HLA association studies for dengue

\begin{tabular}{lllll}
\hline Comparison & HLA alleles & Population & Odds ratio & p \\
\hline DHF vs. DF & $\mathrm{B}^{*} 52$ & Thailand & 0.08 & 0.0049 \\
DHF vs. CTLS & $\mathrm{A}^{*} 0203$ & Thailand & & \\
& $\mathrm{A}^{*} 31$ & Cuba & $7.60(2.3,27.7)$ & $<10^{-4}$ \\
& $\mathrm{~A}^{*} 24$ & Vietnam & 1.54 & 0.02 \\
& $\mathrm{~B}^{*} 52$ & Thailand & $3.01(1.59,5.76)$ & 0.00048 \\
& $\mathrm{DRB1}^{*} 0901$ & Vietnam & $0.37(0.19,0.73)$ & 0.0019 \\
& $\mathrm{DRB1}^{*} 04$ & Cuba & $0.19(0.05,0.63)$ & 0.001 \\
DF vs. CTLS & $\mathrm{B}^{*} 51$ & Thailand & 3.38 & 0.021 \\
& $\mathrm{~B}^{*} 15$ & Cuba & 4.6 & 0.0005 \\
\hline
\end{tabular}

variants in malaria adds compelling evidence to a role for these alleles in immunopathology.

Cytotoxic T-lymphocyte antigen 4 (CTLA-4) is an essential receptor involved in the negative regulation of $\mathrm{T}$ cell activation. CTLA- 4 also plays an important role in the homeostasis and function of regulatory $\mathrm{T}$ cells. Plasma levels of transforming growth factor $\beta-1$ (TGF $\beta 1$ ), an immunosuppressive cytokine, have been associated with DHF. Frequencies of the TGF $\beta 1-509 \mathrm{C} / \mathrm{T}$ polymorphism and the CTLA- $4+49$ polymorphism (associated with clearance of hepatitis B virus) were compared in $100 \mathrm{DHF}$ and 150 DF patients during an outbreak of DEN2 in Taiwan [16]. The TGF $\beta 1-509$ CC genotype frequency was significantly higher in the DHF group compared to DF group (OR 1.94, 95\% CI, 1.04-3.61, $\mathrm{p}=0.034$ ). The presence of the CTLA- $4+49 \mathrm{G}$ allele and TGF $\beta 1-509$ CC was associated with increased risk of DHF (OR 2.1, 95\% CI, $1.07-4.09, \mathrm{p}=0.028)$.

CD8+ T cells are triggered by DENV peptides presented on the surface of infected cells by HLA Class I molecules. These peptides are produced by proteasome-mediated degradation of DENV protein and transported by TAP $1 / 2$ into ER for loading onto HLA [16]. Thus, TAP1/2 can play an important role in determining the selection of peptides for HLA loading and the rate at which the HLA is loaded. A South Indian analysis in 75 DHF and 90 DF patients found a nonsignificant association of the TAP1333 G allele with DHF (OR 1.63, 95\% CI, 0.92-2.89, $\mathrm{p}=0.07$ ) [17]. A subsequent study found that a higher proportion of DHF cases (31\%) had the TAP2 665 THR/ ALA genotype than those with DF (13\%) (OR 2.9, 95\% CI, 1.24-6.77, $\mathrm{p}=0.006$ ).

Polymorphisms in HLA alleles may result in differential $\mathrm{T}$ cell profiles leading to variable antiviral responses [18]. There have been a number of HLA allele associa- tions with DHF and DF, summarized in table 1 [19]. As can be seen, the sample sizes are small and the effect sizes vary. The majority of these studies are quite limited in that they were underpowered, did not have replicate cohorts and did not adjust for multiple comparisons.

In a recent genome-wide association study of 2,008 children with DSS and 2,018 controls from Vietnam, a susceptibility locus at MICB (major histocompatibility complex) class I polypeptide-related sequence B) was identified (20). It was within the broad major histocompatibility complex region on chromosome 6 but outside the class I and class II HLA loci (rs3132468, P(meta) = $4.41 \times 10^{-11}$, per-allele OR = 1.34, 95\% CI, 1.23-1.46 [20]. Another locus identified was within PLCE1 (phospholipase C, epsilon 1) $\left(\mathrm{rs} 3765524, \mathrm{P}(\right.$ meta $)=3.08 \times 10^{-10}$, perallele OR $=0.80,95 \%$ CI, 0.75-0.86.

In summary, despite animal studies and human association studies, the relationship between human immune response gene polymorphisms and susceptibility to neurological complications in WNV infected individuals remains poorly understood. The public health relevance of detecting such associations pertains to either targets for anti-virals or for vaccine development. With the advent of next-generation sequencing, it is possible that variants that are less common may need to be sought. There have been many variants proposed as predisposing for susceptibility to dengue; however, the majority of studies have been limited. Although more rigorously conducted studies are beginning to emerge, more high quality association studies are needed. 


\section{References}

1 Petersen LR, Hayes EB: West Nile virus in the America. Med Clin North Am 2008;92:13071322.

$>2$ Gubler DJ: The continuing spread of West Nile virus in North America. Clin Infect Dis 2007;45:1039-1046.

-3 Mashimo T, Lucas M, Simon-Chazottes D, Frenkiel MP, Montagutelli X, Ceccaldi PE, Deubel V, Guenet JL, Despres P: A nonsense mutation in the gene encoding $2^{\prime}-5^{\prime}$ oligoadenylate synthetase/L1 isoform is associated with West Nile virus susceptibility in laboratory mice. Proc Natl Acad Sci USA 2002;99:11311-11316.

4 Yakub I, Lillibridge KM, Moran A, Gonzalez OY, Belmont J, Gibbs RA, Tweardy DJ: Single nucleotide polymorphisms in genes for 2 ' -5 ' oligoadenylate synthetase and RNase L in patients hospitalized with West Nile virus infection. J Infect Dis 2005;192:1741-1748.

$>5$ Lim JK, Lisco A, McDermott DH, Huynh L, Ward JM, Johnson B, Johnson H, Pape J, Foster GA, Krysztof D, Follmann D, Stramer SL, Margolis LB, Murphy PM: Genetic variation in OAS1 is a risk factor for initial infection with West Nile virus in man. PLoS Pathog 2009; 5:e1000321.

-6 Loeb M, Eskandarian S, Rupp M, Fishman N, Gasink L, Patterson J, Bramson J, Hudson TJ, Lemire M: Genetic variants and susceptibility to neurological complications following West Nile virus infection. J Infect Dis 2011;204: 1031-1037.

7 Bigham AW, Buckingham KJ, Husain S, Emond MJ, Bofferding KM, Gildersleeve H, Rutherford A, Astakhova NM, Perelygin AA, Busch MP, Murray KO, Sejvar JJ, Green S, Kriesel J, Brinton MA, Bamshad M: Host genetic risk factors for West Nile virus infection and disease progression. PLoS One 2011; 6:e24745.
8 Glass WG, McDermott DH, Lim JK, Lekhong S, Yu SF, Frank WA, Pape J, Cheshier RC, Murphy PM: CCR5 deficiency increases risk of symptomatic West Nile virus infection. J Exp Med 2006;203:35-40.

$>9$ Lim JK, Louie CY, Glaser C, Jean C, Johnson B, Johnson H, McDermott DH, Murphy PM: Genetic deficiency of chemokine receptor CCR5 is a strong risk factor for symptomatic West Nile virus infection: a meta-analysis of 4 cohorts in the US epidemic. J Infect Dis 2008; 197:262-265.

10 Lim JK, McDermott DH, Lisco A, Foster GA, Krysztof D, Follmann D, Stramer SL, Murphy PM: CCR5 deficiency is a risk factor for early clinical manifestations of West Nile virus infection but not for viral transmission. J Infect Dis 2010;201:178-185.

11 Gibbons RV, Vaughn DW: Dengue: an escalating problem. BMJ 2002;324:1563-1566.

12 Sakuntabhai A, Turbpaiboon C, Casadémont I, Chuansumrit A, Lowhnoo T, Kajaste-Rudnitski A, Kalayanarooj SM, Tangnararatchakit K, Tangthawornchaikul N, Vasanawathana S, Chaiyaratana W, Yenchitsomanus PT, Suriyaphol P, Avirutnan P, Chokephaibulkit K, Matsuda F, Yoksan S, Jacob Y, Lathrop GM, Malasit P, Desprès P, Julier C: A variant in the CD209 promoter is associated with severity of dengue disease. Nat Genet 2005;37:507-513.

13 Loke H, Bethell D, Phuong CX, Day N, White N, Farrar J, Hill A: Susceptibility to dengue hemorrhagic fever in Vietnam: evidence of an association with variation in the vitamin $\mathrm{D}$ receptor and Fc gamma receptor IIa genes. Am J Trop Med Hyg 2002;67:102-106.
14 Fernández-Mestre MT, Gendzekhadze K, Rivas-Vetencourt $\mathrm{P}$, Layrisse $\mathrm{Z}$ : TNF-alpha308A allele, a possible severity risk factor of hemorrhagic manifestation in dengue fever patients. Tissue Antigens 2004;64:469-472.

15 Vejbaesya S, Luangtrakool P, Luangtrakool K, Kalayanarooj S, Vaughn DW, Endy TP, Mammen MP, Green S, Libraty DH, Ennis FA, Rothman AL, Stephens HA: TNF and LTA gene, allele, and extended haplotype associations with severe dengue virus infection in ethnic Thais. J Infect Dis 2009;199:14421448.

16 Chen RF, Wang L, Cheng JT, Chuang H, Chang JC, Liu JW, Lin IC, Yang KD: Combination of CTLA-4 and TGFB1 gene polymorphisms associated with dengue hemorrhagic fever and virus load in a dengue- 2 outbreak. Clinical Immunol 2009;131:404-409.

17 Soundravally R, Hoti SL: Immunopathogenesis of dengue hemorrhagic fever and shock syndrome: role of TAP and HPA gene polymorphism. Human Immunol 2007;68:973979.

18 Fink J, Gu F, Vasudevan SG: Role of T cells, cytokines and antibody in dengue fever and dengue haemorrhagic fever. Rev Med Virol 2006;16:263-275.

19 Stephens HA: HLA and other gene associations with dengue disease severity. Curr Top Microbiol Immunol 2010;338:99-114.

-20 Khor CC, Chau TN, Pang J, Davila S, Long HT, Ong RT, Dunstan SJ, Wills B, Farrar J, Van Tram T, Gan TT, Binh NT, Tri le T, Lien le B, Tuan NM, Tham NT, Lanh MN, Nguyet NM, Hieu NT, Van N, Vinh Chau N, Thuy TT, Tan DE, Sakuntabhai A, Teo YY, Hibberd ML, Simmons CP: Genome-wide association study identifies susceptibility loci for dengue shock syndrome at $M I C B$ and PLCE1. Nat Genet 2011;43:1139-1141. 